\title{
Pathologic Stage II HPV-Mediated (p16- Positive) Oropharyngeal Carcinoma AJCC v8
}

National Cancer Institute

\section{Source}

National Cancer Institute. Pathologic Stage /I HPV-Mediated (p16-Positive)

Oropharyngeal Carcinoma AJCC v8. NCI Thesaurus. Code C132899.

Stage II includes: (T0, N2, M0); (T1, N2, M0); (T2, N2, M0); (T3, N0, M0); (T3, N1, M0); (T4, N0, M0); (T4, N1, M0). T0: No primary identified. T1: Tumor $2 \mathrm{~cm}$ or smaller in greatest dimension. T2: Tumor larger than $2 \mathrm{~cm}$ but not larger than $4 \mathrm{~cm}$ in greatest dimension. T3: T umor larger than $4 \mathrm{~cm}$ in greatest dimension or extension to lingual surface of epiglottis. T4: Moderately advanced local disease. Tumor invades the larynx, extrinsic muscle of tongue, medial pteryg oid, hard palate, or mandible or beyond. Mucosal extension to lingual surface of epiglottis from primary tumors of the base of the tongue and vallecula does not constitute invasion of the larynx. N0: No regional lymph node metastasis. N1: Tumor with metastasis in four or fewer lymph nodes. N2: Tumor with metastasis in more than four lymph nodes. M0: No distant metastasis. (AJCC 8th ed.) 